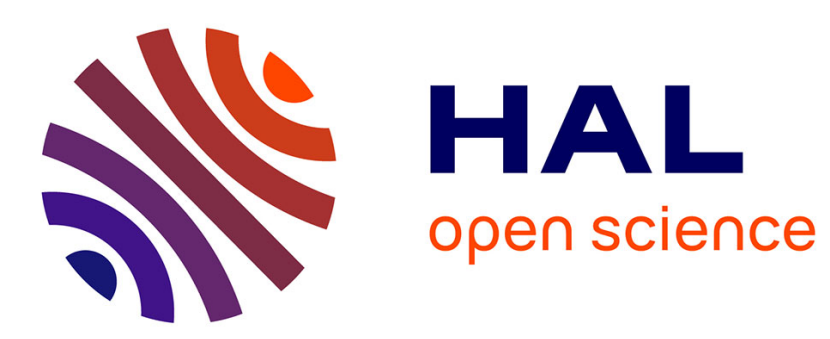

\title{
External Network Modeling for MVAr Scheduling in Multi Area Power Systems
}

Yannick Phulpin, M. Begovic, Marc Petit

\section{To cite this version:}

Yannick Phulpin, M. Begovic, Marc Petit. External Network Modeling for MVAr Scheduling in Multi Area Power Systems. Power Tech 2007, Jul 2007, Lausanne, Switzerland. pp.1-5. hal-00212073

\section{HAL Id: hal-00212073 \\ https://hal-centralesupelec.archives-ouvertes.fr/hal-00212073}

Submitted on 22 Jan 2008

HAL is a multi-disciplinary open access archive for the deposit and dissemination of scientific research documents, whether they are published or not. The documents may come from teaching and research institutions in France or abroad, or from public or private research centers.
L'archive ouverte pluridisciplinaire HAL, est destinée au dépôt et à la diffusion de documents scientifiques de niveau recherche, publiés ou non, émanant des établissements d'enseignement et de recherche français ou étrangers, des laboratoires publics ou privés. 


\title{
External Network Modeling for MVAr Scheduling in Multi Area Power Systems
}

\author{
Y. Phulpin, M. Begovic and M. Petit
}

\begin{abstract}
Multi area power systems work most often with a poor inter-regional coordination about reactive power concerns. Transmission system operators typically do not possess a detailed knowledge about voltage profile across interconnected power systems. In this context, reactive power scheduling may be inefficient and inter-regional reactive power flows become a decisive issue. This inefficiency, associated with economic constraints and increasing stress on interconnection lines, may lead to conflicts, which could be partially avoided with a better scheduling strategy. In addition to inter-utility agreements, part of the solution could be to use appropriate external network modeling. Different modeling are thus presented in this paper and illustrated with an IEEE 118 bus system with 2 separately controlled regions, whose scheduling objective is to minimize active power losses. The regional scheduling process is described and the state of the interconnected power system is compared with a global optimization. Finally, the influence of the external network modeling parameters and the accuracy of their forecast is commented.
\end{abstract}

Index termes - Interconnected Power Systems, Power Systems Planning, Reactive Power Control

\section{INTRODUCTION}

$\mathrm{T}$ HE uncertainty among consumption, generation and transmission systems requires Transmission System Operators (TSOs) to introduce strategies for real-time frequency and voltage control. Hierarchical voltage control strategies have been developed in this framework, most often with a clear distinction between dynamic control, which is basically distributed among all control units, and a longer term regulation, which may be partially scheduled in a regional frame [1] and is commonly referred to as MVAr scheduling.

Following major black-outs, MVAr scheduling has become a key issue [2] and different control schemes have been proposed in order to achieve regional objectives such as minimization of active power losses [3], maximization of the voltage stability [4], or other multi-objective functions [5]-[7].

MVAr scheduling is indeed a variety of optimal power flow (OPF), where each TSO schedules the settings of its transportation systems (tap or phase transformers, capacitor

Y. Phulpin and M. Petit are with the Department of Power and Energy Systems, Ecole Superieure d'Electricite, France (0033-16985-1516; e-mail: yannick.phulpin@supelec.fr, marc.petit@supelec.fr).

M. Begovic is with the School of Electrical and Computer Engineering, Georgia Institute of Technology, Atlanta, GA 30332-0250 USA, (e-mail: miroslav.begovic@ece.gatech.edu). banks, FACTS) and of the output voltage of the generators located in its control area according to its own optimization function. The performance of this local optimization is however limited by the fact that TSOs only have a local knowledge of the power system due to the strategic confidentiality of state and forecast data of interconnected regional power systems, which are driven by other TSOs. Thus, TSOs may only know about power flows or voltage at interconnections and possess a historical record of their values. This paper proposes a comparison of several external network modeling (ENM) methods that TSOs can use in order to schedule the MVAr management in their area.

In first section, a framework for multi-utility optimization of MVAr management is proposed. Then, a review of ENM for regional MVAr scheduling and a method for assessing their parameters are presented. Finally, regional strategies are compared with a global optimization in the case of the IEEE 118 Bus test system with two regions, which is defined in [8].

\section{MVAR SCHEDULING}

\section{A. MVAr Scheduling in an Isolated Power System}

Considering a static demand and a redistribution of the active power injections (distributed slack bus), the MVAr scheduling is the optimization of the control parameters as a function of a selected optimization objective. There are at least five main criteria which can be used to define methods for MVAr scheduling, listed below.

1) State Variables

Centralized voltage control techniques [9] may set all control units parameters according to a general optimization function. This approach requires important computation capabilities and may be difficult to apply in large power systems.

Consequently, many TSOs have decided to use a hierarchical voltage control [10]. In this context, the regional power system is divided into subregions, in which all voltage control units are supposed to maintain the reference voltage of the pilot node [11]. The Tertiary Voltage Control is scheduled by the TSO as the reference voltage of all pilot nodes [3]. It could be compared with a centralized voltage control in a simplified power system. In this paper, we focus on these centralized techniques.

2) Time scale

The MVAr scheduling is based on a forecast of active and 
reactive power demand, which may be forecasted an hour ahead [3]. Some TSOs may optimize their voltage level in real-time [6]. In this paper, it is considered that all regions use an "hour ahead" forecast.

\section{3) Control Variables}

An issue is also to determine what is regulated by the TSO. As their reactive power injection capabilities are greater than those of capacitor banks or FACTS, generators' reactive reserves may be preserved for emergency cases [6]. Further, tap or phase shifting transformers may be used only for active power management. In this paper, generators' and compensators' output voltage, tap and phase transformers settings are considered as controls.

In this study, generators' active power injections are proportional to their initial value (distributed slack bus) and do not serve as control variables.

\section{4) Constraints}

TSOs have a large knowledge base of historical constraint violations and they integrate $\mathrm{N}-1$ security constraints in an optimal power flow. This restriction is more difficult when no history of constraint violations is known. That is why only $\mathrm{N}$ level security constraints (the cases without contingencies) are considered in this paper.

5) Objectives

A decisive characteristic of MVAr scheduling is a choice of the objective function. Most of the TSOs apply a multiobjective function, based on the two following objectives.

Traditionally, a trend is to minimize the active power losses [3]. Practically, TSO maximizes the voltage profile across their region in order to reduce the line currents and therefore minimize losses [7]. This kind of regulation also increases the transfer capacities of existing lines, which are mainly dependent on maximum currents.

Recent focus on voltage stability has lead TSOs to maximize the reactive power reserves [12]. That approach is not considered in this paper.

\section{B. MVAr Scheduling in an Multi Utility Power System}

In a large scale power system, it is common that different TSOs control different regions, which are often interconnected with multiple tie lines in order to enable a common electricity market and to ensure a greater security. However, voltage control remains a prerogative of the local TSO.

\section{1) Local Optimization Function}

A main issue is the choice of the optimization function. TSOs do not always agree on their objectives due to the fact that they do not possess the same reactive power injection capabilities and the same network topology. In this paper, we consider that all regions have the same objective, which is the active power loss minimization.

\section{2) Partial Knowledge of the External Power System}

Another problem is the TSOs' partial knowledge of the external part of the power system. It is assumed that each TSO has a perfect forecast of the demand and of the generation configuration in its own region including voltages and power flows at interconnections, but no knowledge about the network configuration in other regions. An external network model (ENM) thus needs to be used. A probabilistic method is chosen to determine the parameters of such models at interconnections. These two issues are presented in the following section.

Once the ENM is determined, the local optimization must respect the load flow equations at the equivalent network as well as the inter area active power exchanges.

3) Aggregation

All regional MVAr scheduling are confronted in real-time. At this time, all generators' and compensators' output voltage and tap and phase transformers' settings are defined. A new load flow is run with a distributed slack bus and a preservation of interregional active power exchanges.

\section{LOCAL OPTIMIZATION OF MVAR SCHEDULING}

\section{A. External Network Modeling}

There are many ways for representing an external network with little knowledge about it. A large review of equivalents is available in [13]. This paper focuses only on ENM that can be parameterized based on internal measurements. Thus, No ward equivalent [14] is experienced. On the contrary, the following equivalents are studied:

1) REI equivalent

The performance of REI equivalent for interconnection flow scheduling is discussed in [15]. This equivalent consists of an equivalent PV bus, a line connecting with a boundary PQ bus, with no demand and lines connecting each interconnection bus. The parameters of these elements are determined with respect to the last measurements of voltage and apparent power flows at interconnection.

2) Thevenin Equivalent

This equivalent is defined in [16]. A line connects each interconnection bus with a $\mathrm{V}, \delta$ bus. These voltage amplitude and angle are determined according to measurements of voltage and apparent power flows at interconnection by at least 2 different states of the network. The last measurements define the first state while a new power flow with the same control settings and a different load defines the second state.

3) $P Q$ buses

This equivalent is defined in [12] in the context of distributed voltage control. Each interconnection bus is linked by a zero impedance line with a PQ bus whose demand corresponds to last measurements of the active and reactive power flows at the interconnection.

4) PV buses

This equivalent is similar to the $\mathrm{PQ}$ bus, but the zero impedance line connects a PV bus whose active power corresponds to previous measurements of the active power flow while its voltage is the previous voltage at interconnection bus.

\section{B. Local Optimization}

1) Benchmark System

MVAr scheduling is applied to the case of the modified 
IEEE 118 Bus test system, originally defined in [17] and represented in Figure 1. Originally allocated tap changing transformers are operating in the voltage band between maximum (1.05pu) and minimum $(0.95 \mathrm{pu})$. Further, 2 phase shifting transformers have been introduced as a modification of the original scheme at the interconnections:

- between buses 30 and 38, driven by TSO A

- between buses 15 and 33, driven by TSO B

Maximum $\left(28.64^{\circ}\right)$ and minimum $\left(-28.64^{\circ}\right)$ angle deviations have been chosen for those 2 transformers. At all buses, the voltages are set to stay within the limits [0.94pu, 1.06pu].

Considering that MVAr scheduling must respect the economic constraints, active power flow from area A to area B is kept constant and equal (in the base case) to $74 \mathrm{MW}$.

2) Region $A$

The results of MVAr scheduling in region A for different ENM are presented in Figures 2 and 3. Parameters of the equivalents are measured by the initial case defined in [17]. According to the observations mentioned in [7], the minimization of active power losses corresponds to an average voltage profile near its upper limit. However, differences can be observed between the voltage profiles obtained with each equivalent. These deviations depend principally on the limit conditions, which are imposed by the type of equivalent and its parameters' values. It is noticeable in this case that using PV equivalent leads to a much lower voltage profile near the interconnection area, while using PQ, Thevenin and REI equivalents lead to quite similar voltage profiles with slight differences.

3) Region $B$

The results of MVAr scheduling in region B for different ENM are shown in Figures 4 and 5. As for region A, parameters are measured in the initial (base) case. Voltage profiles are very similar to those obtained in area A. The deviations are more important due to the smaller dimension of the network.

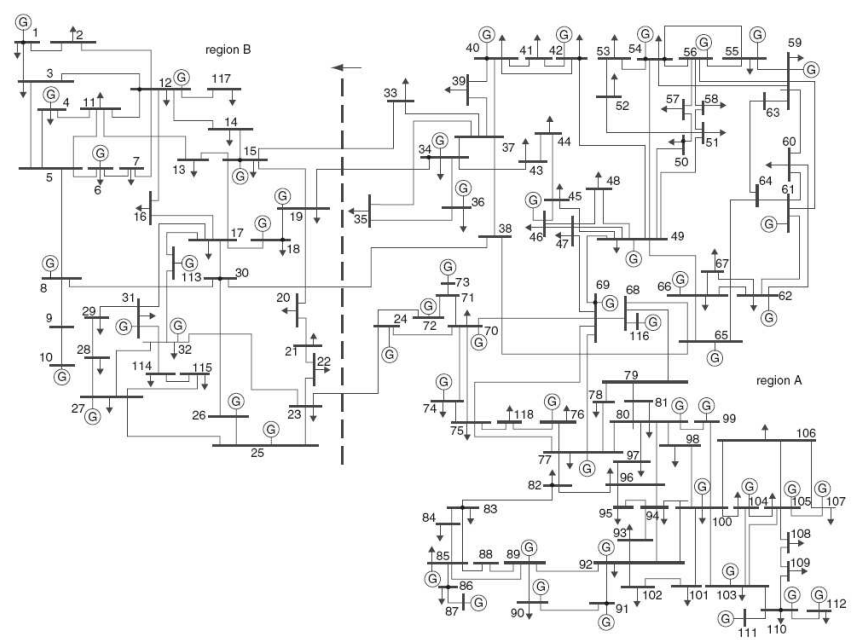

Figure 1: IEEE 118 Bus System with two areas

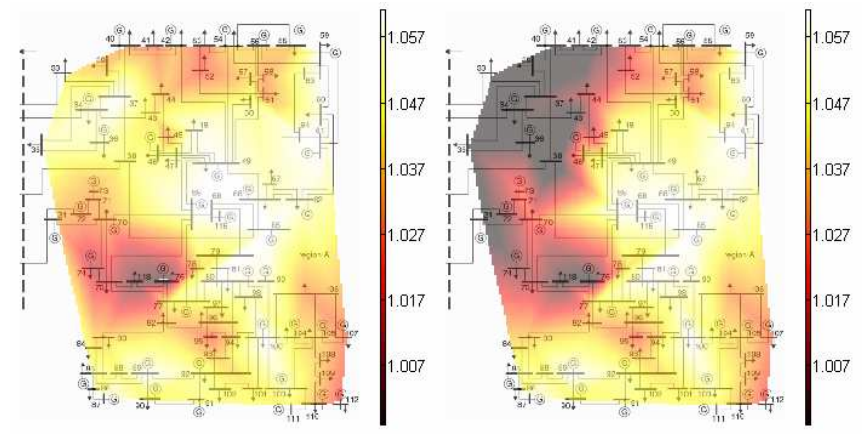

Figure 2: Interpolated voltage level across the Region A of the IEEE 118 Bus System. On the left, a PQ ENM is used. On the right, a PV ENM is used. Voltage is in p.u.

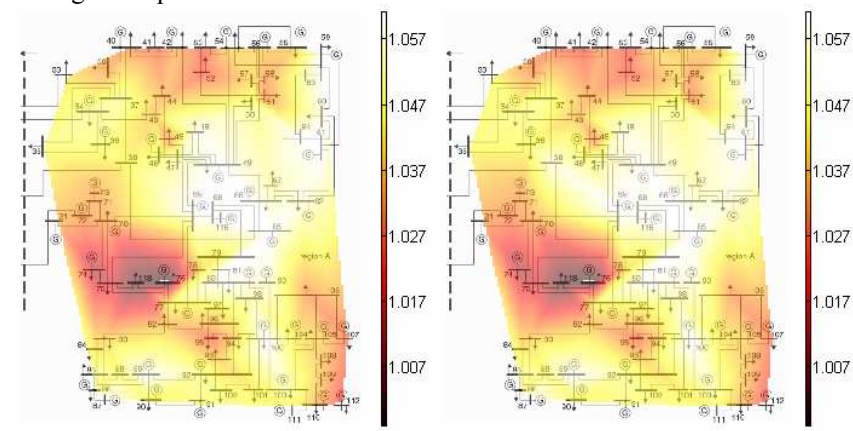

Figure 3: Interpolated voltage level across the Region A of the IEEE 118 Bus System. On the left, a REI Equivalent is used. On the right a Thevenin Equivalent is used. Voltage is in p.u.
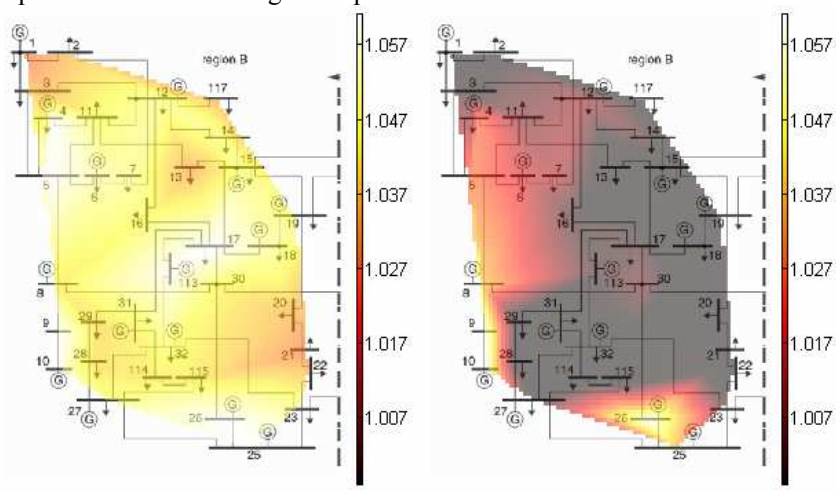

Figure 4: Interpolated voltage level across the Region B of the IEEE 118 Bus System. On the left, a PQ ENM is used. On the right, a PV ENM is used. Voltage is in p.u.
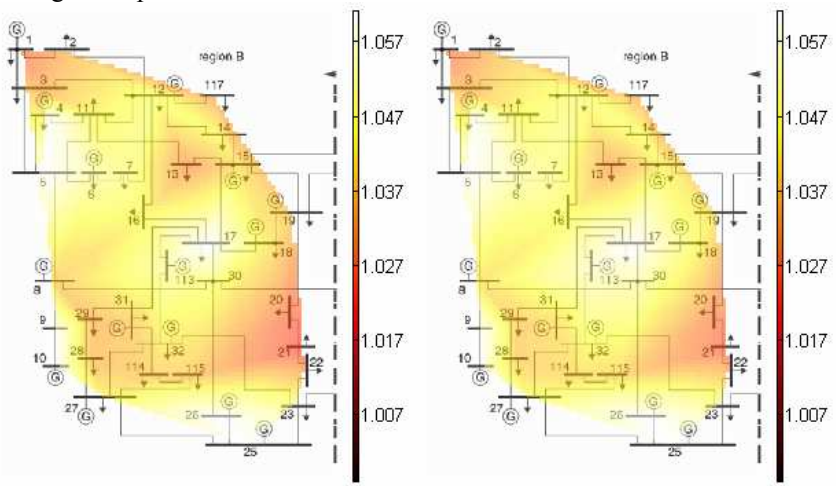

Figure 5: Interpolated voltage level across the Region B of the IEEE 118 Bus System. On the left, a REI Equivalent is used. On the right a Thevenin Equivalent is used. Voltage is in p.u. 


\section{Probabilistic Method to Determine the Parameters}

Each TSO is assumed to define "new" control settings with the parameters issued from the last measurements. They are supposed to store it into a historical record of control variables. Depending on the generation, transmission and distribution forecast, the expected value of the corresponding control variables is then selected as the optimal choice.

In the following base case example, no historical data had been known for the interconnection. This process has thus been simulated. In order to highlight the influence of this step for the final results two sets are studied:

\section{1) Randomly Defined Set}

Parameters of equivalents for local optimization are measured by randomly controlled network with a load factor equal to 1.0. A set of 10 control settings is considered.

\section{2) Nearly Optimal Set}

Parameters of equivalents are measured by global active power loss minimization and reactive power reserve maximization with a load factor varying from 0.8 through 1.2 in steps of $0.1 \mathrm{pu}$. This constitutes a set of 10 different control settings.

\section{CONFrontation With GLOBAL OptimizATION}

After local optimization, controls are applied in the interconnected power system. Active power losses are computed in different cases and presented in Figure 7 and Figure 8. By global OPF, there are 80,8 MW, 34,25 MW and $115,05 \mathrm{MW}$ respectively in region $\mathrm{A}$, region $\mathrm{B}$ and in the interconnected power system.

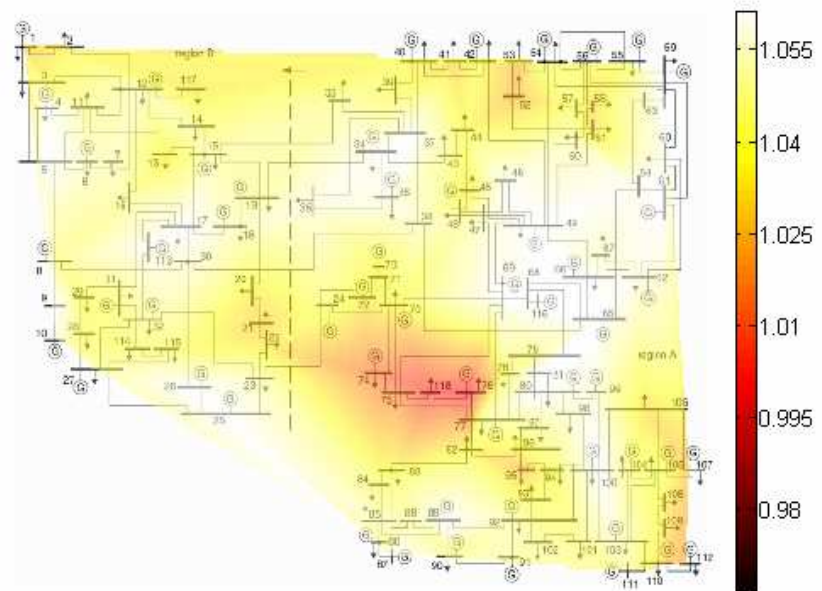

Figure 6: Interpolated voltage level across the IEEE 118 Bus System where the global amount of active power losses has been minimized. Voltage is in p.u.

\section{A. Results by Randomly Defined Set}

As parameters of the ENM are determined according to a random process, the results presented in Figure 7 are not reproducible. However, they represent an average of the observations during the simulations.

It is observed that every studied ENM model leads to a highly suboptimal state. In this context, the fact that optimizations are local is critical for the performance of the system. More precisely, important differences are noticeable between equivalents. By order of efficiency, they can be ranked as follows: 1) PQ equivalent, 2) Thevenin equivalent, 3) PV equivalent and 4) REI equivalent.

Finally, one can observe that the relative level of active power losses is more important in region $\mathrm{B}$ than it is in region A. This difference comes from the smaller dimension of region $\mathrm{B}$ and therefore the lower amount of losses in this region while extra losses are localized near the interconnection and approximately equivalent in each region.

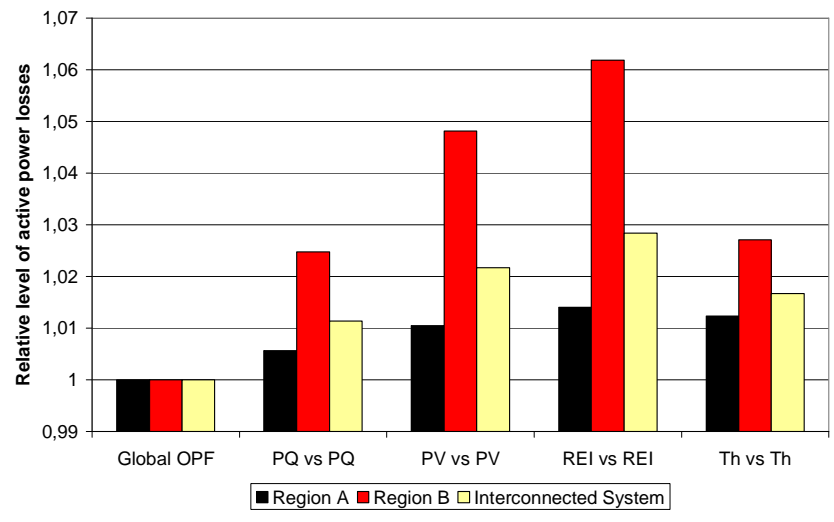

Figure 7: Relative active power losses in Region A, Region B and in the interconnected power system. PQ vs PQ means that region A's MVAr are scheduled with a PQ representation of interconnected areas and so are region B's too. Paraters of the ENM are issued from the randomly defined set.

\section{B. Results by Nearly Optimal Set}

The level of performance reached while using an equivalent is higher in this context although some ENM models still lead to higher operating costs. For instance, using a REI equivalent leads to an increase of $1 \%$ of active power losses in the interconnected power system. With this approach, and according to the observations mentioned in the previous section, PQ equivalent and Thevenin equivalent seem to be more efficient than other ENM.

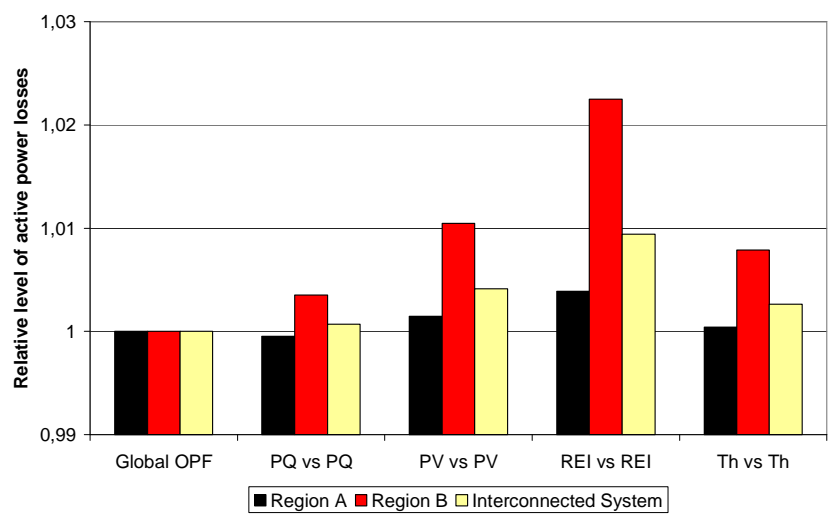

Figure 8: Relative active power losses in Region A, Region B and in the interconnected power system. PQ vs PQ means that region A's MVAr are scheduled with a PQ representation of interconnected areas and so are region B's too. 
The comparison between randomly defined set and nearly optimal set highlights the importance of the ENM parameters. As no measurements are available on the IEEE 118 Bus system, further work is necessary to more accurately evaluate the equivalents. However, the previous observations tend to show that PQ and Thevenin equivalents are interesting options for MVAr scheduling, unlike REI equivalent.

\section{On the Ability to Deliver Clear Forecasts}

Possessing a data base of measurements of currents and voltages at interconnections is not a sufficient condition for achieving a satisfactory level of optimization. Indeed, demand and generation dispatch forecast needs also to be accurate. Although secondary voltage control (which is dedicated to shorter time scale regulation) addresses this issue, it may be seen as a limitation for this study.

Real case observations could however provide with a better knowledge of each equivalent's parameter stability regarding changes in the system configuration. This stability could induce an efficient MVAr scheduling for any limited forecast error and would thus be an interesting step toward more realistic evaluation of equivalents.

\section{CONCLUSION}

This paper shows that certain choices of ENM lead to a more efficient MVAr scheduling in a multi-utility environment. Choosing an ENM model requires a consideration of its performance but also of the ability to forecast accurately ENM parameters. Although the presented example does not amount to a recipe for all systems and situations, it reveals some properties of the ENMs which can be exploited in designing their applications in other networks and for real cases.

\section{REFERENCES}

[1] C. W. Taylor, Power System Voltage Stability, New York: McGraw Hill, 1994

[2] T. Van Cutsem, C. Vournas, Voltage Stability of Electric Power Systems, Kluwer Academic Publishers, 1998

[3] P. Panciatici, F. Bena, P. Pruvot, N. Janssens, J. Deusse, M. Stubbe, «Le Réglage Centralisé de Tension: un Element Clé pour l'Exploitation Optimale des Systèmes Electriques», CIGRE session 1998, Paris, France, Cigré Paper 39-116, 1998

[4] F. Dong, B.H. Chowdhury, M.L. Crow, L. Acar, "Improving Voltage Stability by Reactive Power Reserve Management", IEEE Transactions on Power Systems, vol. 20, No 1, pp. 338-45, Feb. 2005

[5] B. Venkatesh, G. Sadasivam, and M. A. Khan, "A new optimal reactive power scheduling method for loss minimization and voltage stability margin maximization using successive multi-objective fuzzy LP technique", IEEE Transactions on Power Systems, vol. 15, no. 2, pp. 844-851, May 2000

[6] S. Corsi, M. Pozzi, C. Sabelli, A. Serrani, "The Coordinated Automatic Voltage Control of the Italian Transmission Grid-Part I: Reasons of the Choice and Overview of the Consolidated Hierarchical System”, IEEE Transactions on Power Systems, vol. 19, No 4, pp. 1723-1732, Nov. 2004

[7] C.W. Taylor, "Reactive Power Today, Best Practices to Prevent Blackouts", IEEE Power and Energy Magazine, Vol. 4, No 5, pp. $104-$ 102 , Oct. 2006
[8] H. Song, B. Lee, Y.H. Moon, "Reactive Optimal Power Flow incorporating margin enhancement constraints with non linear interior point method", IEE Proceedings on Generation Transmission and Distribution, vol. 152, No 6, pp. 961-968, Nov. 2005

[9] N. Martins, N.J.P. Macedo, L.T.G. Lima, H.J.C.P. Pinto, "Control strategies for Multiple Static VAr Compensators in Long Distance Voltage Supported Transmission Systems", IEEE Transactions on Power Systems, Vol. 8, No 3, pp. 1107-1117, Aug. 1993

[10] Task Force 39-02, «Réglage de la Tension et de la Puissance Réactive», CIGRE session 1992, Paris, France, Cigré Paper 39-203, 1992

[11] J.P. Paul, J.Y. Leost, J.M. Tesseron, "Survey on the Secondary Voltage Control in France: a Present Realization and Investigations", IEEE Transactions on Power Systems, vol. 2, No 2, pp. 505-511, May 1987

[12] M. Zima, D. Ernst, "On Multi-Area in Electric Power Systems", Proceedings of the 15th Power System Computation Conference, PSCC, Liège, Belgium, Aug. 2005

[13] External Network Modeling Task Force, K. Kato Chairman, "External Network Modeling, Recent Practical Experience", IEEE Tranactions. on Power Sysems,, Vol. 9, No. 1, pp. 216-228, Feb. 1991

[14] L. Nepomuceno and A. Santos Jr., "Equivalent optimization model for loss minimization: a suitable analysis approach", IEEE Transactions on Power Systems, Vol. 12, No. 4, pp.1403-1412, Nov. 1997.

[15] M.L. Oatts, S.R. Erwin, J.L. Hart, "Application of the REI Equivalent for Operations Planning Analysis of Interchange Schedules", IEEE Transactions on Power Systems, Vol. 5, No. 2, pp. 547-557, May 1990

[16] B. Milosevic, M. Begovic, "A Network of Phasor Measurement Units for Voltage Stability Monitoring and Control," IEEE Transactions on Power Systems, Vol. 18, No. 1, pp. 121-127, Feb. 2003

[17] R.D. Zimmerman, C.E. Murillo-Sanchez, D.D. Gan, Matpower User's Manual, School of Electrical engineering, Cornell University, Ithaca, Feb. 2005

\section{BIOGRAPHIES}

Yannick Phulpin (S'06) received both degrees in electrical engineering from Supelec in Paris, France, and from the Technical University of Darmstadt, Germany, in 2004. He is currently assistant professor at Supelec and he is pursuing a double $\mathrm{Ph} . \mathrm{D}$. in voltage stability and reactive power management at interconnections with the Georgia Institute of Technology in Atlanta, Georgia.

Miroslav M. Begovic (S'87, M’89, SM'92, F'04) is Professor with School of Electrical and Computer Engineering, Georgia Institute of Technology in Atlanta, Georgia. His research interests are in the general area of computer applications in power system monitoring, protection and control, and design and analysis of renewable energy sources. Dr. Begovic was a Chair of the Working Group "Wide Area Protection and Emergency Control" and ViceChair of the Working Group "Voltage Collapse Mitigation" of the IEEE PES Power System Relaying Committee. He authored a section "System Protection" for the monograph "The Electric Power Engineering Handbook", CRC Press LLC, 2000. Dr. Begovic was a contributing member of the IEEE PES PSRC Working Group "Protective Aids to Voltage Stability", which received the IEEE Working Group Recognition Award in 1997. He is currently serving as Chair of the Emerging Technologies Coordinating Committee of the IEEE PES. Dr. Begovic is a member of Sigma Xi, Tau Beta Pi, Eta Kappa Nu, and Phi Kappa Phi.

Marc Petit is a former student of the Ecole Normale Supérieure de Cachan in Paris, France. He received the Ph-D degree from the University of Orsay, France, in 2002. Currently, he is assistant professor in the power systems group of the Department of Power and Energy Systems of Supelec 